\title{
CONTAMINATION OF SEED CROPS
}

\section{WIND POLLINATION}

\author{
By A. J. BATEMAN \\ John Innes Horticultural Institution, Merton
}

Received I 7.iv. 47

Gross-pollination of seed crops by insects, dealt with earlier in this series (Bateman, 1947), may have seemed to seed growers a difficult problem. Cross-pollination by wind has generally been considered even more difficult to eliminate. Incidentally air-pollination is a more accurate term than wind-pollination as all air movements are effective in distributing air-borne pollen. One can observe insects at work pollinating a crop and their generally regular behaviour immediately impresses one. On the other hand, air currents are invisible, more erratic, and could conceivably carry pollen much farther than insects. Hive bees, by being deprived of all sources of nectar over a large area, can be made to fly up to seven miles from the hive (Eckert, 1933). According to the same author, however, they rarely fly more than two miles from the hive when an ample food supply is near at hand, and any one bee confines herself to a much smaller area than that bounded by a circle of two miles radius. Wind, on the other hand, continues indefinitely, and it is conceivable that individual pollen grains could be carried round the world, though it is most doubtful whether they would be viable after such an ordeal.

In fact, atmospheric pollen has been found at sea-level at all points across the Atlantic ocean between Sweden and New York. Erdtman (1943) analysed the air in mid-ocean during early summer by means of a vacuum cleaner, and found the concentration of pollen grains to be 0.7 grain per Ioo cubic metres. At this point the commonest genera were Betula and Pirus. The comparable figure for the Swedish mainland was 18,0oo grains per Ioo cubic metres.

In view of these differences between insects and wind in the possible maximum distances over which they could carry contaminant pollen, it was thought desirable to carry out experiments on the effects of distance on contamination in two wind pollinated crops, beet and maize.

Beet, though generally regarded as wind pollinated, is probably to some extent pollinated by flies. In open flowers a disc, moist with nectar, is plainly visible, between stamens and style. The anthers, though hinged, are not versatile and flies of various kinds, including hover flies, can be seen visiting these flowers, though they do so 
erratically and spend much of their time walking over other parts of the inflorescence searching for nectar. In 1944 an experiment was carried out, designed to assess the relative importance of wind and insects in pollinating spinach beet. Cages of various kinds constructed to exclude wind and flies, wind alone or flies alone, were placed over individual plants; but all caged plants died, even those in which the cage was open at the top.

\section{EXPERIMENT I-BEET}

Spinach Beet and red beet of the variety Crimson Ball were used, for with the former as seed parent, hybrids can be recognised at a very early stage among the progeny. Even the radicle emerging from the germinating seed is suffused with the anthocyanin introduced by Crimson Ball pollen.

The first attempt was a failure. The two varieties were sown at the same time in one year and planted out in the following spring in an arrangement similar to that described in the previous paper for turnips (Bateman, 1947). There was a square of Crimson Ball with arms to east and west three rows wide of Spinach Beet. The two varieties scarcely overlapped in flowering time, Spinach Beet bolting much earlier than Crimson Ball. Consequently, of the thousands of test progeny grown, only one contaminant seedling was observed. This served to emphasise the importance of isolation in time as a means of preventing contamination.

The following season the Crimson Ball was sown a month earlier than the Spinach Beet. In this way a greater degree of overlapping was obtained than the year before. The Crimson Ball was, however, much poorer in growth than the Spinach Beet. The central contaminating plot consisted of 169 plants of Crimson Ball. There were two arms of Spinach Beet, running north and south, each consisting of three rows. All plants were 9 inches apart each way. The north and south arms had 87 plants and 102 plants per row respectively. The three rows were designated $a, b$ and $c, a$ being the eastern and $c$ the western row. The first five plants of each row were harvested and after that every fifth plant. All seed from each plant was harvested and a representative sample sown in $\mathrm{r} 2$-foot drills so that up to 400 seedlings were obtained from each tested plant. Some plants produced a very poor seed crop, so for each distance the results from the three rows were pooled and the contamination calculated from the pooled date (see table r).

It will be seen at once that the maximum contamination is very small, about to per cent. This is probably due to the fact that in spite of their longer growing period the Crimson Ball plants produced much smaller inflorescences than the Spinach Beet. Their pollen would therefore be swamped by the Spinach Beet. There is no apparent difference between contamination in the two arms though 
one might expect some in a wind-pollinated crop. The similarity between the general distribution of contamination in this and in the

TABLE I

\begin{tabular}{|c|c|c|c|c|c|c|}
\hline \multirow{2}{*}{$\begin{array}{l}\text { Distance (unit } \\
\text { is } 9 \text { inches) }\end{array}$} & \multicolumn{3}{|c|}{ S series } & \multicolumn{3}{|c|}{$\mathbf{N}$ series } \\
\hline & Hybrid & Total & F & Hybrid & Total & F \\
\hline I & $3^{8}$ & 373 & $\cdot 1019$ & 54 & $53^{2}$ & IOI 5 \\
\hline 2 & 26 & 334 & $\cdot 077^{8}$ & 15 & 244 & .0615 \\
\hline 3 & $\mathbf{I}$ & 3 & $\cdot 3333$ & 12 & 293 & .0410 \\
\hline 4 & 7 & 301 & .0233 & 10 & 443 & .0226 \\
\hline 5 & 6 & 245 & $\cdot 0245$ & 8 & 263 & .0304 \\
\hline 10 & 7 & 331 & .0211 & 3 & 304 & . oog9 \\
\hline 15 & I & 268 & -0037 & 5 & 595 & $\cdot 0084$ \\
\hline 20 & 3 & 205 & -0146 & 5 & 586 & $\cdot 0085$ \\
\hline 25 & 2 & 185 & -0108 & o & 6 & $\cdot 0000$ \\
\hline 30 & o & $39^{2}$ & $\cdot 0000$ & 0 & 7 & $\cdot 0000$ \\
\hline 35 & o & 29 & $\cdot 0000$ & 2 & $49^{6}$ & .0040 \\
\hline 40 & o & 136 & $\cdot 0000$ & 1 & $47^{\circ}$ & $\cdot 002 \mathrm{I}$ \\
\hline 45 & o & 28 & . & 2 & 419 & $\cdot 0048$ \\
\hline 50 & o & 10 & $\cdot 0000$ & 0 & 409 & $\cdot 0000$ \\
\hline 55 & o & 142 & - 0000 & 0 & 212 & .0000 \\
\hline 60 & o & 475 & .0000 & o & 8 & $\cdot 0000$ \\
\hline 65 & o & 197 & $\cdot 0000$ & 1 & 455 & $\cdot 0022$ \\
\hline 70 & 1 & 236 & $\cdot 0042$ & o & 79 & $\cdot 0000$ \\
\hline 75 & o & 108 & .00oo & o & 255 & $\cdot 0000$ \\
\hline 80 & 0 & 434 & $\cdot 0000$ & 0 & $53 \mathrm{I}$ & $\cdot 0000$ \\
\hline $8_{5}$ & $\mathbf{I}$ & $79 \mathrm{I}$ & .001 3 & o & 671 & $\cdot 0000$ \\
\hline 90 & $I$ & 419 & .0024 & $\ldots$ & $\cdots$ & $\ldots$ \\
\hline 95 & o & 376 & '000o & $\ldots$ & $\cdots$ & $\cdots$ \\
\hline 100 & 0 & 271 & $\cdot 0000$ & $\ldots$ & $\ldots$ & $\ldots$ \\
\hline
\end{tabular}

Contamination figures in Experiment $I$ over distances up to 75 feet. The actual sizes of the test progenies are given to show which results are the most reliable. $F$ is used as the symbol for the proportion of hybrid seed.

previously discussed radish and turnip experiments (loc. cit.) is very striking in view of the differences in pollination mechanisms. There is the same rapid fall over short distances but with a residual amount persistent up to relatively large distances.

\section{EXPERIMENT \|-MAIZE}

Though the role of insects in beet pollination is uncertain, there is no doubt about the identity of the pollinating agent in maize. Bees often visit the tassels to collect pollen but they do not visit the silks.

A plot was laid out parallel to Experiment I. The contaminant plot consisted of 144 plants of Early Yellow Flint, II feet square with $\mathrm{I}$ foot spacing each way. The stringers consisted of a single row of Canada Gold with 2 feet spacing. Using these varieties contamination is measured as the proportion of flinty seeds on the Canada Gold ears. The $\mathcal{N}$ stringer extended for 84 feet, the $S$ stringer for 78 feet. Though the two varieties overlapped to a great extent in flowering period, the flint corn was slightly earlier than the sweet corn. Canada Gold, being an open pollinated variety, showed 
considerable individual variation in flowering time and in the interval between tasselling and silking. This meant that, cutting right across the variation in contamination due to isolation distance, there was variation due to earliness of silking and the degree of protandry. The latter is important in a sparsely planted stringer such as was used, because of its determination of the amount of non-contaminant pollen available at silking. There might also be expected variation between the cobs on one plant arising from their sequence of silking. On the other hand, the non-uniformity in time of tasselling of the Early Yellow Flint variety only serves to provide a steadier and longer supply of contaminant pollen, thereby reducing the error variation of contamination.

To provide a check on any variation not due to isolation distance, periodic surveys were made to obtain approximate dates of pollen shedding (not tasselling) and silking of all Canada Gold plants. Also, when harvesting, made a note of the position of the ear on the plant. This provides a record of the order of flowering since the highest ear on the main axis is the one which has silked first the tillers being always later. Where tillers produced terminal female or hermaphrodite ears instead of tassels this was also recorded.

TABLE 2

\begin{tabular}{|c|c|c|c|c|c|c|c|}
\hline $\begin{array}{c}\text { Distance from } \\
\text { contaminant in feet }\end{array}$ & $\begin{array}{l}\text { Plant } \\
\text { no. }\end{array}$ & $\begin{array}{l}\text { North } \\
\text { stringer }\end{array}$ & $\begin{array}{l}\text { South } \\
\text { stringer }\end{array}$ & Dist. & $\begin{array}{l}\text { Plant } \\
\text { no. }\end{array}$ & North & South \\
\hline 2 & I & $* .7014$ & $\ldots$ & 44 & 22 & .0000 & $\cdot 0000$ \\
\hline 4 & 2 & $\cdot 0667$ & *.5359 & 46 & 23 & $\cdot 0000$ & *.oogr \\
\hline 6 & 3 & *. 5724 & $\ldots$ & 48 & 24 & $* .0275$ & $\cdot 0000$ \\
\hline 8 & 4 & *.3222 & $* \cdot 455^{2}$ & 50 & 25 & .0000 & *.0000 \\
\hline 10 & 5 & $\cdot 1170$ & - 0127 & 52 & 26 & *.0106 & *.oror \\
\hline 12 & 6 & .0324 & $\ldots$ & 54 & 27 & $\cdot 0240$ & .0000 \\
\hline 14 & 7 & $\cdot 0075$ & $* .0272$ & 56 & 28 & .0000 & $\cdot 0000$ \\
\hline 16 & 8 & .0151 & *. 1042 & 58 & 29 & *.oog 6 & .0000 \\
\hline 18 & 9 & $\cdot 0000$ & .0118 & 60 & 30 & *.0120 & *.or 45 \\
\hline 20 & Io & $* .4190$ & $\cdot 008 \mathrm{I}$ & 62 & $3^{r}$ & $* .0270$ & $\cdot 0000$ \\
\hline 22 & I I & $\cdot 0038$ & $\cdot 0000$ & 64 & $3^{2}$ & $\ldots$ & $* .0032$ \\
\hline 24 & I 2 & $\ldots$ & $\ldots$ & 66 & 33 & $\ldots$ & $\cdot 0000$ \\
\hline 26 & 13 & $* .1231$ & *.0207 & 68 & 34 & $\ldots$ & 0000 \\
\hline 28 & 14 & *.0354 & $* .0616$ & 70 & 35 & ${ }^{*} \cdot 0163$ & $* .0000$ \\
\hline 30 & 15 & $* .0610$ & *.0317 & 72 & 36 & *.003 I & *.0300 \\
\hline 32 & 16 & $\cdot 0062$ & .0000 & 74 & 37 & $* 0036$ & $* .0000$ \\
\hline 34 & 17 & $\ldots$ & *.0132 & 76 & 38 & *.or 59 & $\cdot 0000$ \\
\hline 36 & 18 & .0000 & *.006 3 & 78 & 39 & $* 0000$ & *.0000 \\
\hline 38 & 19 & *.o659 & $\cdot 0000$ & 80 & 40 & $\ldots$ & $\ldots$ \\
\hline 40 & 20 & .0000 & .0000 & 82 & $4^{I}$ & $\cdot 0060$ & $\ldots$ \\
\hline 42 & 21 & $* .0578$ & $\cdot 0000$ & 84 & $4^{2}$ & $\cdot 0000$ & ... \\
\hline
\end{tabular}

Figures for contamination in Experiment II. Results marked with a * are those obtained from plants which silked before I th August. Gaps are due either to the death of the plant or to obstructions (64-68 in the $\mathrm{N}$ series).

Table 2 shows the contamination per plant as a result of pooling all ears sufficiently mature to be scorable. It is immediately obvious 
that there is a large error variation. Table 3 shows the times of pollen shedding and silking of all plants in both stringers. Comparison

TABLE 3

First observation of pollen-shedding

\begin{tabular}{|c|c|c|c|c|c|c|c|c|c|c|c|c|}
\hline \multirow[b]{2}{*}{$\begin{array}{l}\text { North } \\
\text { stringer }\end{array}$} & \multirow{2}{*}{\begin{tabular}{llll}
\multicolumn{4}{c}{$31 / 7$} \\
& & & \\
10 & 15 & 18 & 21 \\
24 & 26 & 27 & 29 \\
31 & 35 & 36 & 38
\end{tabular}} & \multicolumn{2}{|r|}{$5 / 8$} & $9 / 8$ & \multicolumn{3}{|c|}{$11 / 8$} & \multicolumn{3}{|c|}{$14 / 8$} & \multirow{2}{*}{$\begin{array}{c}16 / 8 \\
20222341\end{array}$} & $22 / 8$ \\
\hline & & $\begin{array}{r}\mathbf{I} \\
30\end{array}$ & 41419 & 3 & 6 & 13 & 37 & 5 & 8 & 16 & & $\begin{array}{rrr}2 & 7 & 11 \\
25 & 28 & 39\end{array}$ \\
\hline $\begin{array}{l}\text { South } \\
\text { stringer }\end{array}$ & $\begin{array}{rrrr}2 & 3 & 4 & 7 \\
8 & 13 & 14 & 17 \\
36 & & & \end{array}$ & $\begin{array}{ll}15 & 2 \\
32 & 3\end{array}$ & 382630 & $\begin{array}{llll}18 & 20 & 29 & 33 \\
35 & 37 & 39 & \end{array}$ & 10 & 15 & 27 & $\begin{array}{r}9 \\
21\end{array}$ & $\begin{array}{l}11 \\
22\end{array}$ & $\begin{array}{l}16 \\
24\end{array}$ & $\begin{array}{llll}5 & 19 & 28 & 31\end{array}$ & $6 \quad 1234$ \\
\hline
\end{tabular}

First observation of silks

\begin{tabular}{|c|c|c|c|c|c|c|c|c|c|c|}
\hline & $31 / 7$ & & $5 / 8$ & $9 / 8$ & $x \mathrm{I} / 8$ & & $14 / 8$ & & I6/8 & $22 / 8$ \\
\hline $\begin{array}{l}\text { North } \\
\text { stringer }\end{array}$ & $3^{8}$ & $\begin{array}{rr}I & x \\
35 & 3\end{array}$ & $\begin{array}{ll}15 & 27 \\
36 & \end{array}$ & $\begin{array}{rlll}4 & 10 & 19 & 21 \\
24 & 29 & 31 & \end{array}$ & $\begin{array}{rrrr}3 & 13 & 14 & 26 \\
30 & 37 & 39 & \end{array}$ & $\begin{array}{r}5 \\
22\end{array}$ & 61820 & $\begin{array}{r}8 \\
42\end{array}$ & $164 I$ & $\begin{array}{rrr}2 & 7 & 11 \\
23 & 25 & 28\end{array}$ \\
\hline $\begin{array}{l}\text { South } \\
\text { stringer }\end{array}$ & 36 & 142 & $26 \quad 30$ & $\begin{array}{rrrr}2 & 4 & 7 & 8 \\
17 & 23 & 32 & 37\end{array}$ & $\begin{array}{llll}13 & 15 & 18 & 25 \\
35 & 39 & & \end{array}$ & $\begin{array}{ll}9 & 10 \\
21 & 27 \\
38\end{array}$ & $\begin{array}{lll}10 & 19 & 20 \\
27 & 29 & 33\end{array}$ & II & 2431 & $\begin{array}{rrr}3 & 5 & 6 \\
16 & 22 & 3^{8}\end{array}$ \\
\hline
\end{tabular}

Experiment 11. The numbers of plants are recorded under the dates when they were first seen to be shedding pollen and when they were first seen to be silking.

of the two tables shows i Ith August to be a critical date. Plants silking after that date show very little contamination, but plants silking before that date show appreciable contamination. If separate curves are drawn for the two classes of plants the effect of distance is seen to be much more regular and the error variance has largely disappeared. This is seen in fig. I. Here it can be seen that contamination is generally higher in the $\mathcal{N}$ stringer than in the $S$ stringer. The prevailing wind during the flowering period was south-west, so the cause of the difference is obvious.

There still appear to be a few anomalous plants. Examination of their pollen shedding and silking records, however, throws considerable light on their behaviour. For example, Plant $\mathcal{N}$ io gives too high a contamination $(0.4190)$. It had already begun to shed its pollen on 3 Ist July, but the first silks did not appear until gth August. Thus self-pollination is almost ruled out. The nearest plants shedding pollen on 9th August were $\mathcal{N}_{14}$ to leeward and $\mathcal{N}_{4}$ to windward. Another plant with anomalously high contamination is $S_{36}$. This had its silks out on 3 Ist July when there was very little Canada Gold pollen about, though Early Yellow Flint was shedding much pollen.

As in all previous experiments, over short distances there is a rapid fall in contamination with increasing distance, though the fall then continues gradually as the isolation distance becomes larger. Though great weight cannot be attached to it at this stage, it appears 
that the contamination continues to decrease with increasing distance at all distances in the experiment. As maize is the only completely wind-pollinated crop dealt with so far, this is possibly of some importance. It might be traceable to a basic difference in the modes of action of insects and wind in pollination.

Where the requisite ears were available, an analysis of variance was carried out to test the effect within the plant of time of silking on contamination. The first ears on the main axis had greater contamination than the later ears on the main axis, the first ears on the tillers and the terminal cobs on the tillers. Though none of these

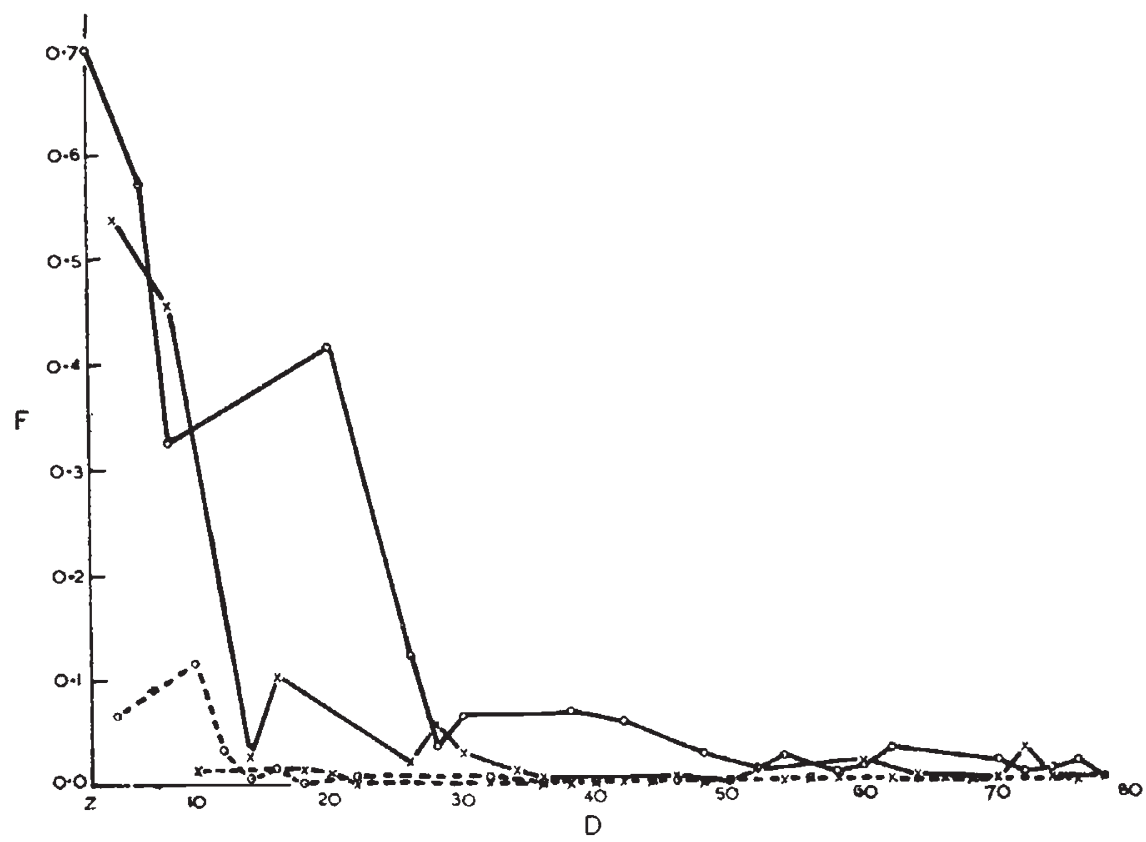

FIG. I.-Experiment II. Graph showing relation between contamination F, and isolation distance in feet, $\mathrm{D}$.

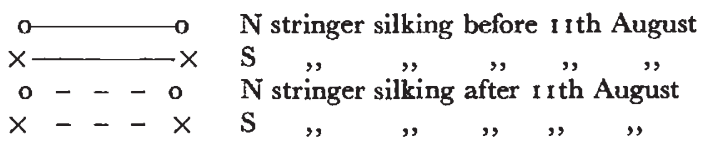

differences were significant, they were all in the direction to be expected from the effect of time on the contamination of individual plants.

In spite of the thin spacing (a single row of plants 2 feet apart) there appeared to be an adequate pollen supply, as most of the ears showed a seed set of 90 per cent. or more. This was so even at the ends away from the contaminant plot. There were a few exceptions which proved the rule. Ten plants of Canada Gold had a seed set of less than 70 per cent. Of these five produced their silks before 
$5^{\text {th }}$ August and three on or after 22nd August, that is, before or after the main production of Canada Gold pollen. The two remaining plants were badly attacked by smut.

The weather conditions were generally dull and damp throughout the flowering period, which may have adversely affected the dispersal of the pollen. This would raise the percentage set in a sparsely planted plot, and would also reduce the extent of contamination.

\section{EXPERIMENT II-POLLEN DISPERSAL IN MAIZE}

One may perform an experiment on contamination in a windpollinated crop like maize, in such a way that variability of the contaminated variety in tasselling, silking, etc., is completely eliminated as a source of error. This was done by dispensing with the contaminated variety. In other words the plants exposed to contamination were replaced by slides coated with gelatine all exposed at the same height above ground, at the same time and for the same period, the only variables being the distance and direction from the source of pollen.

The density of the deposit of maize grains on the slide was measured by adding to the slide a drop of glycerine containing basic fuchsin, placing over it a $\frac{3}{4}$-inch square coverslip, and counting the number of maize grains under the coverslip. Though pollen of other species was deposited on the gelatine, maize grains were readily distinguishable if only by their large size.

A series of exposures was made for a number of days under varying meteorological conditions to assess the effects of rain, wind velocity and direction, etc. In this experiment, at each site two slides were exposed back to back in an erect position, as shown in the inset to fig. 2, 3 feet above ground level and protected from the rain by a small tin lid. With the exception of site $\mathrm{O}$, one slide faced towards the centre of the maize block and one slide faced away from it. This arrangement would throw some light on the effect of atmospheric turbulence on pollen dispersal, i.e. the deviation of the paths of flight of pollen grains from straight lines.

Fig. 2 shows the arrangement of the exposed slides, the pollen source, and the position of wind breaks. The five exposures were made at the times and under the conditions shown in table 5 .

The results for each distance in each stringer for each of the five exposures are shown in table 4. For the sake of clarity the sum of the two back-to-back slides is given for each site. In the Grand Total the figures for site o have been multiplied by 3 . These results are shown graphically in fig. 3. In order, however, to show the variation between the two slides, the grand totals for all stringers are partitioned into $(a)$ the number of grains on the side facing the pollen source, and $(b)$ the number of grains on the other slide of the pair. For site $\mathrm{o}$ at the centre of the source $(a)$ and $(b)$ have been chosen 
arbitrarily, (a) being westward facing. At sites I, which are just within the borders of the pollen source, $(a)$ faces towards the majority of the plants and $(b)$ towards a few of them. Therefore, though on the average $(a)$ should have more pollen than $(b)$, the relative amounts

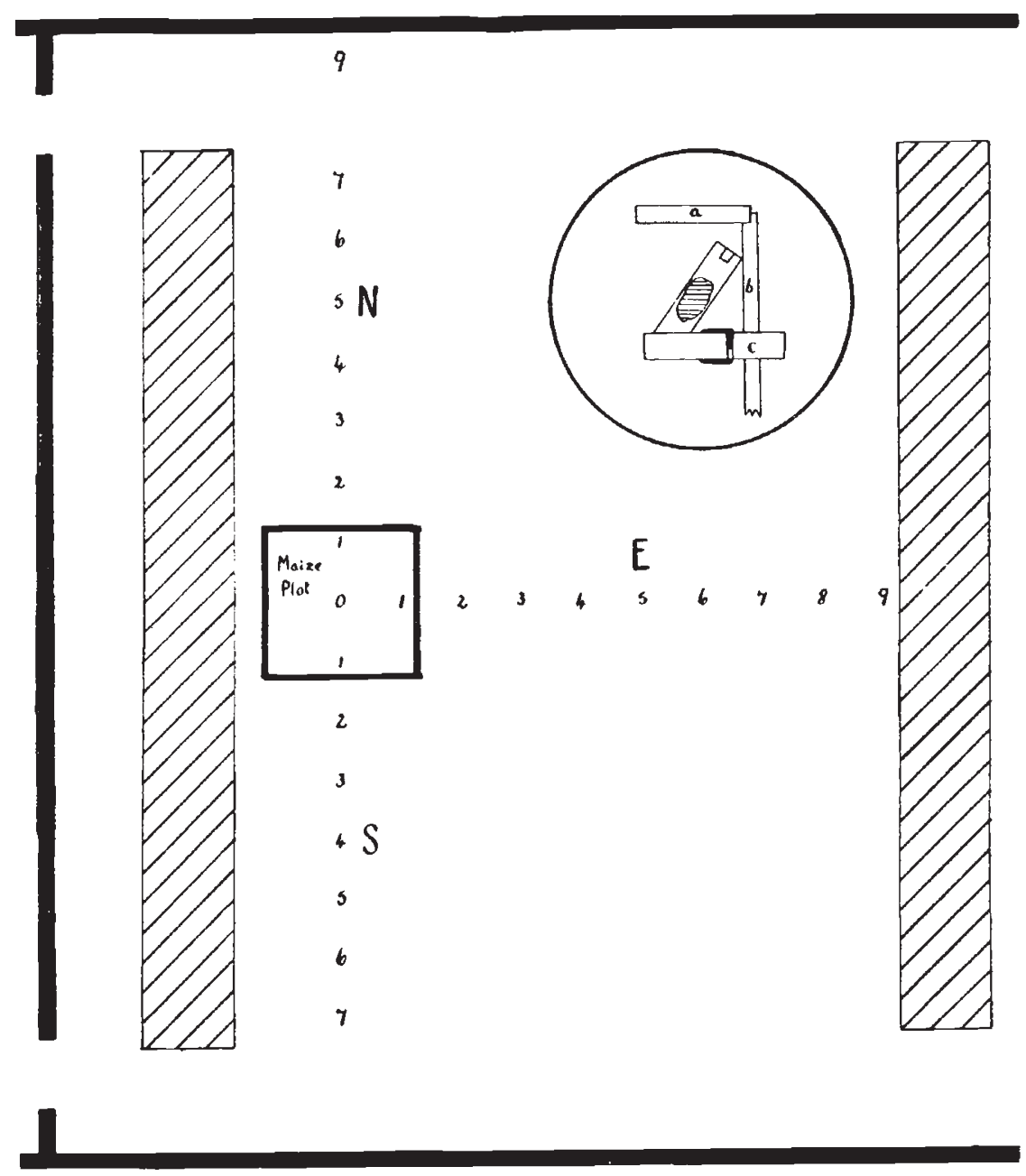

FIG. 2.--Experiment III. Plan of field showing arrangement of sites for exposures relative to maize plot. The thick black lines round the field represent a ro-foot wall. The hatched areas represent bush fruit trees. Inset : Diagram showing method of exposing slides; (a) protective tin lid; (b) 3-foot cane inserted in ground; (c) clothes-peg gripping cane and back-to-back slides on which the gelatined area is shown shaded.

in each case will vary with the wind direction. For this reason the difference between $(a)$ and $(b)$ is less marked at sites $O$ and I than at the remainder, which clearly show that maize pollen tends to drift in straight lines and thus is only rarely deposited on the slide facing away from the source. 
TABLE 4

Experiment III. The number of pollen grains per site per exposure.

\begin{tabular}{|c|c|c|c|c|c|c|c|}
\hline \multicolumn{2}{|l|}{ Exposure } & $\mathbf{I}$ & 2 & 3 & 4 & 5 & $\begin{array}{l}\text { Site } \\
\text { Totals }\end{array}$ \\
\hline & o & 1104 & 626 & 296 & $3^{80}$ & 89 & 2495 \\
\hline Stringer E. & $\begin{array}{r}1 \\
1 \\
2 \\
3 \\
4 \\
5 \\
6 \\
7 \\
8 \\
9 \\
9\end{array}$ & $\begin{array}{r}327 \\
18 \\
1 \\
1 \\
1 \\
0 \\
0 \\
0 \\
0\end{array}$ & $\begin{array}{r}1036 \\
210 \\
55 \\
32 \\
35 \\
14 \\
12 \\
6 \\
1\end{array}$ & $\begin{array}{r}410 \\
71 \\
21 \\
17 \\
6 \\
4 \\
1 \\
0 \\
0\end{array}$ & $\begin{array}{r}199 \\
7 \\
2 \\
0 \\
0 \\
0 \\
0 \\
0 \\
0\end{array}$ & $\begin{array}{r}16 \mathbf{I} \\
21 \\
7 \\
6 \\
4 \\
4 \\
1 \\
0 \\
0\end{array}$ & $\begin{array}{r}2133 \\
327 \\
86 \\
56 \\
46 \\
22 \\
14 \\
6 \\
1\end{array}$ \\
\hline Total per exposure & - $\quad 2-9$ & $2 \mathrm{I}$ & 365 & 120 & 9 & 43 & \\
\hline Stringer N. & $\begin{array}{r}1 \\
2 \\
3 \\
4 \\
5 \\
6 \\
6 \\
7 \\
9\end{array}$ & $\begin{array}{r}319 \\
39 \\
2 \\
2 \\
2 \\
0 \\
0 \\
0\end{array}$ & $\begin{array}{r}313 \\
16 \\
0 \\
1 \\
0 \\
1 \\
0 \\
0\end{array}$ & $\begin{array}{r}234 \\
3 \\
2 \\
0 \\
0 \\
0 \\
0 \\
0\end{array}$ & $\begin{array}{c}819^{*} \\
9 \\
0 \\
0 \\
1 \\
0 \\
0 \\
0\end{array}$ & $\begin{array}{r}116 \\
11 \\
5 \\
3 \\
0 \\
0 \\
0 \\
0\end{array}$ & $\begin{array}{r}1801 \\
78 \\
9 \\
6 \\
3 \\
1 \\
0 \\
-0\end{array}$ \\
\hline Total per exposure & . $\quad 2-9$ & 45 & 18 & 5 & 10 & 19 & \\
\hline Stringer S. & $\begin{array}{r}1 \\
2 \\
3 \\
4 \\
5 \\
6 \\
7\end{array}$ & $\begin{array}{r}1335 \\
125 \\
43 \\
17 \\
10 \\
2 \\
3\end{array}$ & $\begin{array}{r}971 \\
271 \\
95 \\
37 \\
16 \\
12 \\
3\end{array}$ & $\begin{array}{r}343 \\
91 \\
31 \\
8 \\
7 \\
2 \\
1 \\
1\end{array}$ & $\begin{array}{r}592 \\
174 \\
76 \\
29 \\
39 \\
17 \\
9\end{array}$ & $\begin{array}{r}155 \\
7 \\
1 \\
0 \\
0 \\
0 \\
0\end{array}$ & $\begin{array}{r}3396 \\
668 \\
246 \\
91 \\
72 \\
33 \\
16\end{array}$ \\
\hline Total per exposure & . $\quad 2-7$ & 200 & 434 & 140 & 344 & 8 & \\
\hline $\begin{array}{l}\text { Deduced wind directio } \\
\text { Total grains counte } \\
\text { exposure }\end{array}$ & d per & $\begin{array}{l}\text { N.E. } \\
335^{\prime}\end{array}$ & $\begin{array}{l}\text { N.W. } \\
3763\end{array}$ & $\begin{array}{l}\text { N.W. } \\
{ }_{154^{8}}\end{array}$ & $\begin{array}{l}\text { N.E. } \\
2353\end{array}$ & $\begin{array}{l}\text { S.W. } \\
59^{1}\end{array}$ & \\
\hline
\end{tabular}

\begin{tabular}{|c|c|c|c|}
\hline Site & Grand total & \multicolumn{2}{|c|}{ Partitioned } \\
\hline $\begin{array}{l}0 \\
1 \\
2 \\
3 \\
4 \\
5 \\
6 \\
7 \\
(8) \\
(9)\end{array}$ & $\begin{array}{r}7485 \\
7330 \\
1073 \\
341 \\
153 \\
121 \\
56 \\
30 \\
6 \\
1\end{array}$ & $\begin{array}{r}(a) \\
3^{156} \\
5230 \\
1057 \\
33^{8} \\
15^{1} \\
119 \\
54 \\
30 \\
6 \\
1\end{array}$ & $\begin{array}{r}(b) \\
4329 \\
2100 \\
16 \\
3 \\
2 \\
2 \\
2 \\
0 \\
0 \\
0\end{array}$ \\
\hline
\end{tabular}

The grand total is the sum of all stringers and all exposures for each distance and is partitioned into $(a)$ slide facing towards maize block and $(b)$ slide facing away from maize block. For comparison with the others the o total has been multiplied by 3 in the Grand Total figures.

* Slide $\mathrm{N}_{\mathrm{I}}$, exposure 4 , showed clumped grains as might arise if birds had scattered pollen on to it. 
TABLE 5

\begin{tabular}{|c|c|c|c|c|c|}
\hline No. & Time and duration & Wind force & $\begin{array}{l}\text { Average } \\
\text { direction }\end{array}$ & $\begin{array}{l}\text { Maximum } \\
\text { temperature }\end{array}$ & Rain \\
\hline $\begin{array}{l}\mathrm{I} \\
2 \\
3 \\
4 \\
5\end{array}$ & 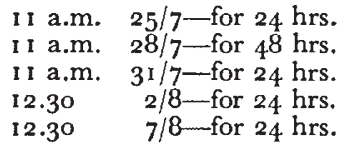 & $\begin{array}{l}\text { Slight wind } \\
\text { Steady breeze } \\
\text { Slight breeze } \\
\text { Slight wind } \\
\text { Strong wind }\end{array}$ & $\begin{array}{l}\text { N.E. } \\
\text { N.W. } \\
\text { N.W. } \\
\text { N.E. } \\
\text { S.W. }\end{array}$ & $\begin{array}{l}73 \\
72 \\
71 \\
78 \\
56\end{array}$ & $\begin{array}{l}\text { trace } \\
\text { trace } \\
\text { none } \\
\text { none } \\
.07 \text { in. }\end{array}$ \\
\hline
\end{tabular}

From the totals for sites from 2 upwards in each arm we can deduce the mean wind direction during each exposure.

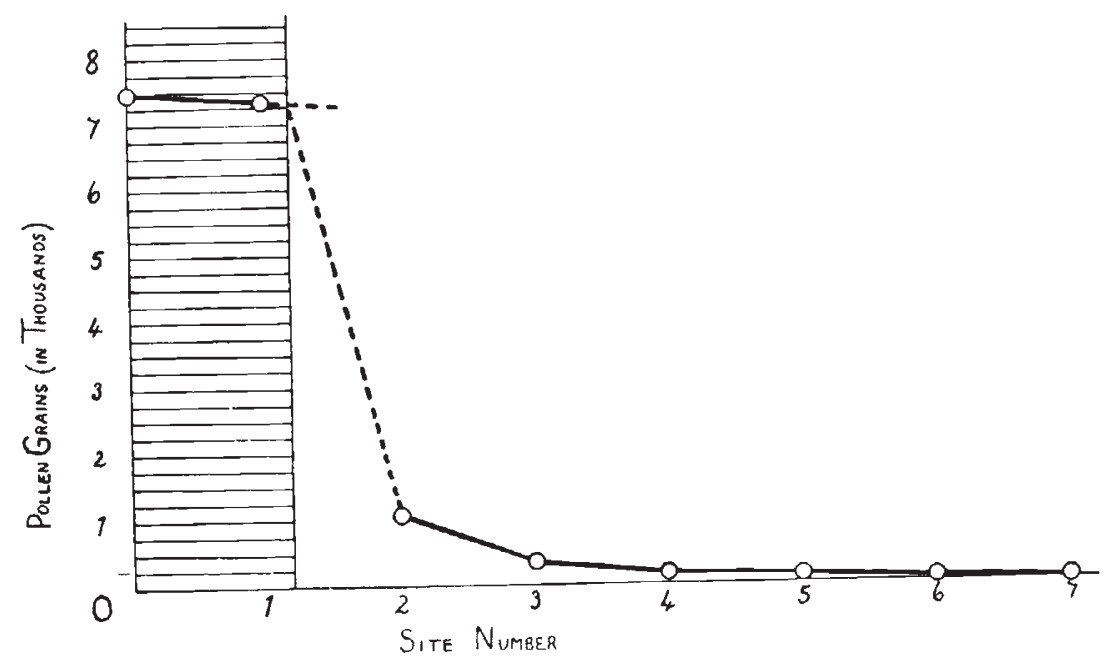

Fig. 3.- Experiment III. Total numbers of pollen grains for all exposures and all three stringers at each distance from the centre of the maize plot. For comparison the number of grains at site o has been multiplied by 3. The shaded area represents the maize plot.

As to the general effect of distance on pollen distribution or contamination, these results show, with much less error variation than Experiment II, that maize pollen is not carried very far. With regular increases in isolation distance the dangers of contamination will diminish rapidly at first, but more and more slowly as the isolation distance becomes greater.

\section{CONCLUSIONS}

Neither beet nor maize are typical wind-pollinated species. Beet has members of the Diptera as supplementary pollinating agents. Maize has excessively large grains which are consequently less buoyant than grains of other anemophilous plants. They will not therefore be distributed so widely by a given wind. 
Even in the grasses, however, with very buoyant pollen, one would expect the curve relating contamination to distance to be of the same basic shape as in maize, the difference residing in the slope. This is shown in a large series of experiments carried out by Jensen and Bøgh (194I). They observed the numbers of pollen grains deposited on vaseline-smeared slides exposed down-wind from large plots of the following crops : rye grass, timothy grass, cocksfoot, rye and sugar beet. In all cases the distances involved were very much greater (o-1 200 metres) than in the above experiments.

In the cases of rye grass and cocksfoot there is an appearance of a minimal value beyond 500-60o metres of about one-twentieth the concentration at the source. This might represent the general level in the atmosphere due to other sources, which would be increased by misclassification of pollens which might well arise in the grasses. If, however, we allow for the difference in scale of the distances for grasses and sugar beet and for maize the shape of the frequency curve is strikingly similar in Jensen and Bøgh's diagram and in the maize results published herein.

In Experiment III of the previous paper in this series (Bateman, 1947) it was shown that the smaller the mass of the contaminated variety the more gradual was the slope of the curve. Increased buoyancy of pollen would have an effect similar to that of decreased mass. It is reasonable to suppose, therefore, that the effect of buoyancy in grass pollen could be counteracted by increasing the mass of the variety.

In spite of the differences between the pollination behaviour of maize and beet and between both of these and the entomopliilous species dealt with earlier (loc. cit.), they all show substantially similar relationships between contamination and isolation distance. In every case a great reduction in contamination is produced by the first ten to twenty feet, and though contamination continues to decrease with increasing isolation distance beyond this point, the rate of decrease becomes steadily smaller. We can conclude, therefore, that though significant differences between wind-pollinated and insect-pollinated plants may be disclosed later, the evidence so far does not justify the use of isolation distances of different orders of magnitude in these two kinds of crop.

\section{SUMMARY}

Beet and maize were used for a study of the influence of distance in reducing cross-pollination, i.e. in effecting isolation in windpollinated crops, under conditions conducive to cross-pollination.

In beet, Carter's strain of Spinach Beet was exposed to contarnination from red beet of the variety Crimson Ball. The maximum contamination (at distance zero) was low (ro per cent.) because of the relatively small inflorescences of the red beet. With increasing 
distance, contamination rapidly declined. At 30 feet it was i per cent. of the maximum.

In maize, Canada Gold (sweet corn) was contaminated by Early Yellow Flint, contamination being discernible on the ripe ear. The results were similar but there was a distinct variation in contamination with direction from the contaminant, variation attributable to the wind direction being mainly south-west. One per cent. contamination was observed at 50 feet in the northern direction and 40 feet in the southern direction.

In both crops the rate of decrease in contamination steadily decreased with increasing isolation distance.

A high error variance between plants of Canada Gold was found to be due to variation in their silking time (female flowering). Latesilking plants missed the main flowering period of the contaminant variety, and therefore had less contamination than earlier plants at similar distances.

In the following year the use of glycerined slides to trap pollen grains around a maize plot produced evidence completely corroborating the previous contamination results. Here the time factor was eliminated from error variation. A distance of 60 feet was sufficient to reduce atmospheric pollen to I per cent. of the concentration obtaining within the plot.

The results of other workers on pollen dispersal in herbage grasses and beet, after due allowance has been made for a greater buoyancy of pollen in these crops, agree with the present maize results.

One may conclude that the requirements in respect of isolation distance of wind-pollinated and insect-pollinated crops are similar. The greater buoyancy of the pollen of some wind-pollinated crops could be allowed for by increasing the size of plots liable to contamination.

Acknowledgment.-This work has been carried out under the auspices of the Agricultural Research Council. The author also wishes to express his gratitude to Dr K. Mather for his advice.

\section{REFERENCES}

BATEMAN, A. J. (1947.)

Contamination of seed crops, I. Insect pollination.

7. Genet, $48,257$.

ECKERT, J. E. 1933.

The flight-range of the honey bee.

Journal of Agricultural Research, 47, 257.

ERDTMAN, G. 1943 .

An introduction to pollen analysis, p. 180. (Chronica Botanica Co.)

JENSEN, I., and BøGH, H. I 94 I.

On conditions influencing the danger of crossing in the case of wind-pollinated cultivated plants.

Tidssk Planteavl., $46,238$. 